\title{
Life Cycle simulation for verifying sustainable model of products
}

\author{
M. Johansen \\ Department of Production Technology, Narvik Institute of Technology \\ Lodve Langes gate 2, 8500 Narvik, Norway
}

Y. Umeda and T. Tomiyama

Department of Precision Machinery Engineering, Graduate School of Engineering, The University of Tokyo

Hongo 7-3-1, Bunkyo-ku, Tokyo 113, Japan

Telephone: + 81-3-3812 2111(ext. 7776), Fax: +81-3-3812-8849

e-mail: \{umeda, tomiyama\}@zzz.pe.u-tokyo.ac.jp

\begin{abstract}
This paper presents a life cycle model with a simulation tool which can be used at a early stage of the design process. The main objective is to evaluate the possibility of reducing the total volume of waste related to mass production and mass consumption. In order to verify the objective, an example is presented.
\end{abstract}

Keywords

Life cycle simulation, post mass production paradigm, closed loop life cycle, modular products

\section{INTRODUCTION}

Some decades ago industry alone was more or less considered responsible for environmental damage. However, it is not industry but the industrial society with mass production that creates main part of the environmental damage. Due to the technological development, consumers have frequently been offered products with better quality to a lower price based on the principles as " the bigger, the better" or "the more, the better." As a result of this development, quantity of discarded products is rapidly growing.

One of the most evident effects is that the landfill capacity is being used up. In Tokyo they have landfill capacity only for 15 more years. Figure 1 shows that this landfill problem is caused mainly by cars, household appliances and consumer electronic goods.

We only have this planet to survive on, and the resources on the earth are limited, as well as its capacity of coping with pollution and waste. These problems coupled with expected exponential grow in world's consumption and force us to react promptly.

Based on the fact that a modern life cycle economy can only function if the polluter takes the responsibility and the cost for recovering and disposing the waste, the Germany government 
has adopted a new act regarding "environment policy concept of the closed substance cycle and waste management," which forces the producers to take fully responsibility for their products based on the principles "from the cradle to the tomb."

ISO has started to develop a new 14000-standard regarding the environment. The new ISO 14000 Environmental Management Systems (EMS) specifies requirements for an environmental management system. This type of regulations and standards force the producers to take the responsibility for their products "from the cradle to the tomb." As a consequence, the producers have to deal with issues such as disassembly, reuse and recycling.

The purpose of implementing a "closed life cycle loop" is to minimize the volume of waste by reusing and recycling all parts of the product, with keeping quality of life and profits of producers in the same level.

In this paper, first, we the environmental background and a contents of Post Mass Production Paradigm (PMPP) which has a strong relationship to the environmental issue in Section 2 . Then, Section 3 illustrates a simulation model of closed life cycle loop we have developed and an example of simulation result is shown in Section 4. After describing some pending factors in Section 5 , Section 7 concludes this paper.

Cars

Household appliances

Consumer electronics

Control equipment

Lighting system

Information system

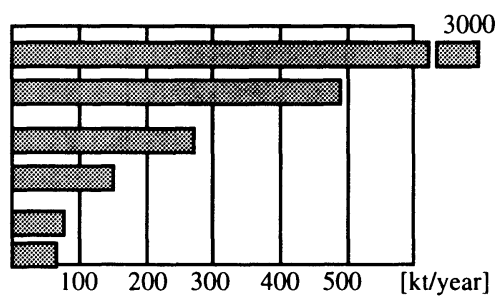

Figure 1: Yearly scrap rate for consumer products in Germany (Hentschel, 1993 ).

\section{POST MASS PRODUCTION PARADIGM}

In order to achieve the aim of reducing the volume of waste, we have proposed Post Mass Production Paradigm (PMPP) (Tomiyama, et. al., 1996). PMPP represents a new production paradigm which aims at reducing production of artifacts in terms of volume, but at the same time keeping up the same standard of living. PMPP suggests a way to overcome the growing environmental issues by decoupling economic growth from resource and energy consumption and waste creation. It is a system of economic activity capable of encouraging and sustaining economic growth without depending on mass production and mass consumption that inevitablly involves the problems mentioned in Section 1. PMPP includes shift of objective of production of artifacts from today's quantitative sufficiency to more qualitative satisfaction.

In order to implement PMPP, a new methodology to reduce the production of artifacts in terms of volume, while maintaining and improving living standard has to be developed as well as a new type of artifacts. A "knowledge intensive society" is a society where economic development is based on the creation of high value products that depend on intellectual recourses rather then natural recourses. In this concept, knowledge plays a decisive role and a major change will take place from " more, cheaper and better products" to " quickly deliver innovative products that can offer better and more responsive service to customers' demand." 


\subsection{Redefining manufacturing industry as life cycle industry.}

The present manufacturing industry provides services from marketing through sales, however reclamation, recycling and discarding of waste are normally outside of its domain. Due to the limitations imposed by the environment, manufacturing industry will be forced to gradually provide services in the later stages of the product's life cycle. When the industry has to consider the total life cycle, the life cycle price of a product has to be defined in order to include costs currently ignored in the market. For example, the price of "single-use camera" is determined in such a manner. Because the single-use camera is in part reused and the rest recycled, it can be understood that its price consists of film price, unlimited rental fee, and insurance fee against, e.g., loss and damage.

Under PMPP, manufacturing industry will clearly be recognized as and expected to serve as life cycle industry (see Figure 2). In the craft society, reclamation and recycling were carried out by nature, while in the industrial society local communities provide these services paid mainly by taxes. In the knowledge intensive society, reuse and recycling should be performed by manufacturing industries. In other words, the focus of the manufacturing industry expands into all stages of product life cycle.

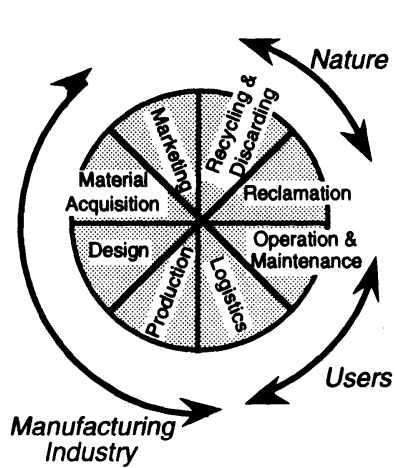

(1) Craft Society

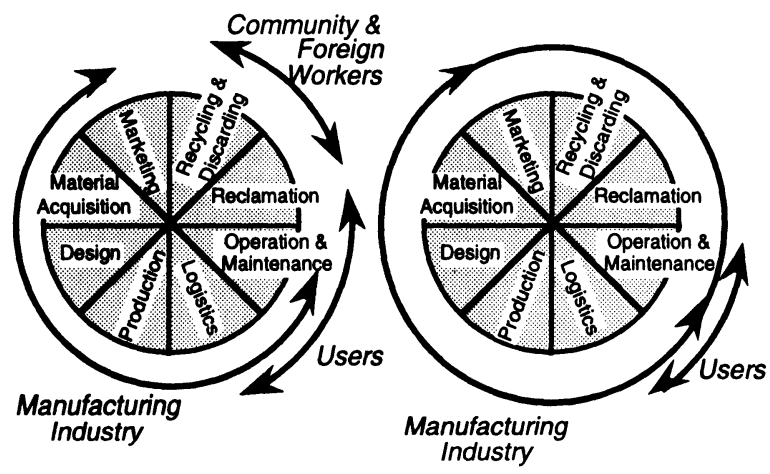

(2) Industrialized Society

(3) Knowledge Intensive Society

Figure 2: Craft, industrialized, and knowledge intensive societies (Tomiyama, et. al., 1996).

\section{LIFE CYCLE SIMULATION}

The aim of the life cycle simulation is to verify how the volume of waste can be reduced and what effect it will have on energy and material consumption. We have constructed a model for this simulation based on some assumptions in order to verify the aim of PMPP. Details of this model are described below.

This model is a general model, and is not built for any specific product. The aim is to make a "template" which, with some small modifications, can be used for several products such as household applicants and consumer electronics.

\subsection{Module based closed life cycle}

There are several ways to reduce the volume of waste. One is to encourage reuse and recycling of the entire product. The other is to divide the product into modules. whenever a module is 
broken, it is replaced by a new module. In other words, some modules can live "forever" and others have limitations. Therefore, if we make a module based product, we can increase life time of the product by replacing a broken module with a new module instead of throwing away the entire product whenever the product is broken. The broken module will then be reused and recycled.

In this simulation, we introduce a module based product into a closed life cycle loop. In order to close the life cycle loop, processes such as disassembly, reuse and recycling should be implemented. Not only broken products are thrown away, we often want new and upgraded products even though the old one is still working. One of the advantages of the module based product is that a product can be upgraded without throwing away the entire product by replacing some modules.

Figure 3 depicts an example of the closed loop life cycle with the involved processes. In this closed loop of product life cycle, whenever a product is broken, the product is either maintained or dismissed for disassembly. From disassembly some parts will be reused and the rest goes to recycling either as material or energy. Material and reusable parts are then either sold or sent back to the manufacturing process. From use, maintenance, disassembly and recycling there will always be some waste. But the objectives of this model include to try to get this volume as small as possible.

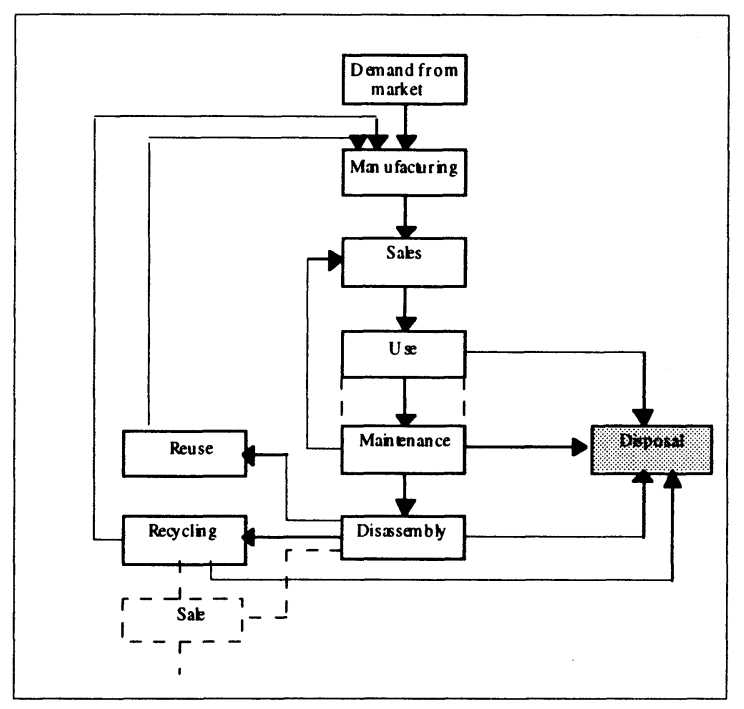

Figure 3: A closed life cycle loop.

\subsection{Parameters}

The model is built in order to examine influents of different numbers of modules and their life time.

\section{Evaluation Parameters}

In order to verify feasibility of the Post Mass Production Paradigm, we evaluate the following parameters in this model ; 
- volume of disposal (EP1),

- energy consumption (EP2), and

- material consumption (EP3).

Here, we evaluate these parameters relatively by dividing these values in the module based product life cycle by those values in the traditional product life cycle.

\section{Given Parameters}

For executing the simulation, values of some parameters should be given by the user. On of the objectives of this simulation includes to support a designer to design and optimize a product life cycle based on results of this simulation by varying these given parameters. The given parameters should be determined based on real figures from the production. The given parameters considered here are as follows. The user should specify values of these parameters before executing the simulation.

- Cost all expenses involved in each processes such as labor, material, and assembling.

- Profit total demand of profit by the producer in each month.

- Distribution coefficients the distribution coefficients has to be decided in various outputs. For example, a distribution coefficient represents how large percentages of disassembled modules go to reuse, recycling and disposal.

- Size of market this parameter denotes a fixed demand from the market in each month.

- Energy used energy used for, e.g., manufacturing, operation and recycling, in each process.

- Raw material after subtracting reused and recycled material which can be used in the manufacturing process, some new material are compensated for material that became waste and was used for energy recycling.

- Number of modules number of modules in each product.

- Life time the estimated life time of each module.

\subsection{Processes in the life cycle model}

In this model, we have chosen to divide the life cycle into nine different processes. Each process is represented by given parameters, output parameters, input parameters and equations.

Given parameters requires user's input before executing simulation. In other words, the user can examine optimal evaluation of each given parameter by executing a lot of simulations with this life cycle simulation tool. Each process calculates values of the output parameters with the equations from the given parameters and the input parameters of which values are propagated from other processes (see Figure 4). Links between the processes represent these propagation paths. 


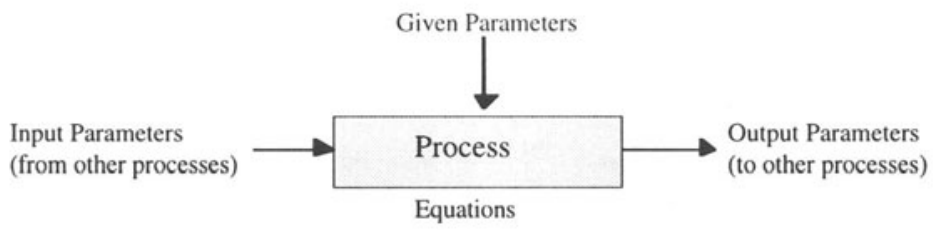

Figure 4: Example of a process in the model.

The following processes are considered in the simulation model:

1) Market

This is the fundamental process of all production. This process provides data regarding number of modules in a product and the life time of each module, which are determined by design.

Given parameters:

* size of market

* number of modules

* life time of each module

* needed material for modules

2) Manufacturing

A product is assembled in the manufacturing process. This process calculates how much new raw material is needed by comparing the demand from the market with available reused and recycled components. This process also calculates the manufacturing cost by using the information given to the model together with the feedback values gained from the disassembly and recycling processes.

Given parameters:

* cost of raw material

* assembly cost

* cost of energy

* amount of energy used in the process

Input parameters:

* amount of reusable modules and recycled material provided from the disassembly and recycling processes.

* cost of reusable modules and recycled material provided from the disassembly

3) Sales and recycling processes.

The product is brought out to the consumer in this process. The profit is divided into each module and are added to the manufacturing cost before the total price of the product is calculated.

Given parameters :

* profit demand

4) Maintenance

Whenever a module is broken, it needs to be replaced with a new module, and this modification is what is called maintenance.

Given parameters :

* cost of maintenance

* cost of energy 
* amount of energy needed for replacing modules

* distribution coefficient that denotes percentage of replaced modules which go to disassembly. The rest goes to disposal. Input parameters :

* number of broken modules in a month

5) Disassembly

Given parameters:

* cost of disassembling a module

* cost of energy

* amount of energy needed for disassembling a module

* distribution coefficients representing percentage of modules that go to reuse, recycling and disposal Input parameters:

* number of modules to be disassembled in a month

6) Reuse

Some modules can be reused without any additional work. In this model, the reuse process is represented as a path of modules from the disassembly process to the manufacturing process.

7) Recycling

The recycling process consists of material recycling and energy recycling. In general, it is difficult to determine how large part supposed to be recycled as material and how large part goes to energy recycling. There is no certain rule for it and it has to be determined depending on kinds of material used in the module with the help of this simulation tool.

Given parameters :

* cost of recycling

$*$ cost of energy

* amount of energy needed in this process

* distribution coefficient representing percentages of modules that go to material recycling, energy recycling and disposal Input parameters :

* number of modules sent to this process in a month

8) Disposal

This process summarizes the volume of disposal sent from the maintenance, disassembly and recycling processes.

Given parameter:

$* \operatorname{tax}$

Input parameters:

* number of modules sent to this process in a month

\subsection{Simulation tool}

The simulation tool is used for planing the life cycle of a product at the very early stages of design in order to support to designers to design the product and its life cycle at the same time. Figure 5 depicts an example of the life cycle model in this simulation tool. 


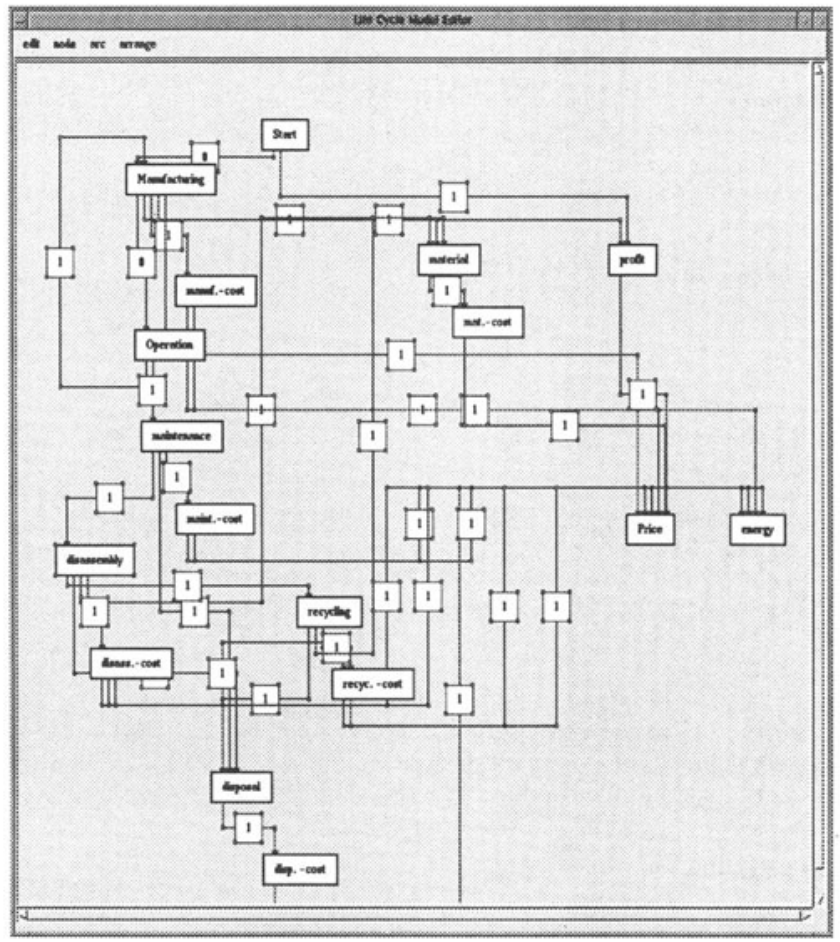

Figure 5: Simulation model.

\section{SIMULATION EXAMPLE}

\subsection{Assumptions}

In order to verify advantages of the module based product in the closed life cycle loop, we here compare its simulation result with the result gained from the module based product in an open life cycle loop. In the open loop, processes like reuse and recycling are not introduced. Moreover, in order to see influences of difference in number of modules in a product, the following assumptions have been made :

- One product consists of ten components

This assumption means that total size, weight and functionality of a product are the same regardless how many modules the product has.

- One product can consists of any number of modules 
- All modules in a product contain the same number of components

This assumption is introduced for simplifying the simulation. Namely, each module consists of $10 / N$ components, where $N$ denotes number of modules in a product.

Table 1 shows values of main given parameters in this simulation example. Moreover, in some processes, the distribution coefficients should be determined. For instance, from the process of disassembly some modules are reused, others go to recycling and the rest is just thrown away. For this simulation, the distribution coefficients are chosen as shown in Table 2. For a real life situation, the distribution coefficients should be determined based on experiences and facts.

For executing the simulation, number of modules and their life time have to be determined. In order to verify influences of module based production, we perform the simulation with different numbers of modules; namely $1,3,5$ and 7 modules in a product. The reason of selecting 1 module is to verify influents of recycling and reuse of non modular products.

\section{Table 1: Given parameters}

\begin{tabular}{ll}
\hline Size of Market & 30 [product / month] \\
It takes 50 months to introduce the new product into the market. \\
Material Cost & 30 [money / product] \\
Assembly Cost & 50 [money / product] \\
Energy for Assembly & 10 [energy / module] \\
Maintenance Cost & 20 [money / module] \\
Energy for Maintenance & 8 [energy / module] \\
Disassembly Cost & 50 [money / module] \\
Energy for Disassembly & 8 [energy / module] \\
Recycling Cost & 100 [money / product] \\
Energy for Recycling & 20 [energy / module] \\
Disposal Tax & 50 [money / product] \\
\hline
\end{tabular}

Table 2: Distribution Coefficients

\begin{tabular}{ccccc}
\hline Process & Reuse & $\begin{array}{c}\text { Material } \\
\text { Recycling }\end{array}$ & $\begin{array}{c}\text { Energy } \\
\text { Recycling }\end{array}$ & Disposal \\
\hline Disassembly & $25 \%$ & $55 \%$ & ---- & $20 \%$ \\
Recycling & $-\cdots---$ & $45 \%$ & $25 \%$ & $30 \%$ \\
\hline
\end{tabular}

The minimum life time of a module is set to 50 months, and the maximum to 200 months. The average life time of each product is between 60 - 150 months.

\subsection{Simulation Results}

\section{Disposal}

If the average life time of a module based product is lower then that of a non module based product, the amount of disposal will be larger. Figure 6 shows the result of simulation in terms of volume of disposal evaluated by the evaluation parameter EP1. In this simulation, the traditional products, of which life time is 70 months, are submitted for disposal when the life time is gone. A increasing life time is one of the benefits of a module based product.

There is no doubt that the most significant reduction in the volume of disposal is gained by introducing recycling and reuse. However, introduction of recycling and reuse is not longer a question, but only a matter of time because all producers are forced to implement and perform 
it sooner or later. A guideline could be to firstly sort out components that are suitable for reuse and have highest value. Then the components that can not be reused directly should go to material recycling. The rest should be used for energy recycling.

If we look upon the results from the closed life cycle and compare one module based products with the seven modules based products, the big gain in reduction of disposal volume appears when the module based product is fully introduced to the market. After this time, the market is mainly based on upgrading and changing modules with only some few "new sell."

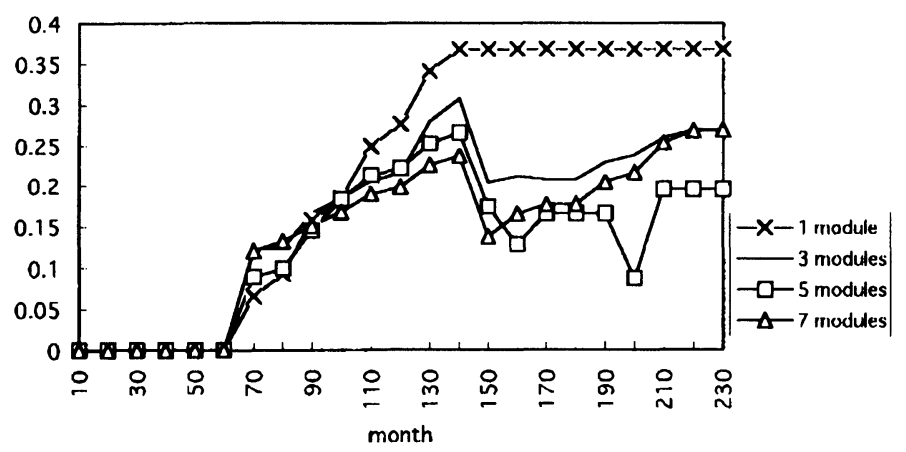

Figure 6: Evaluation of disposal.

\section{Material consumption}

By introducing recycling and reuse, reduction of material consumption will not appear before the end of life time of modules. According to the simulation result, the major gain appears when module based products are fully introduced to the market.

\section{Energy consumption}

The simulation result shows no large difference in terms of the energy consumption. Even though introduction of maintenance, disassembly and recycling might increase the energy consumption, the gain from the energy recycling compensates this increase. Figure 7 shows the simulation result based on the evaluation parameter EP2.

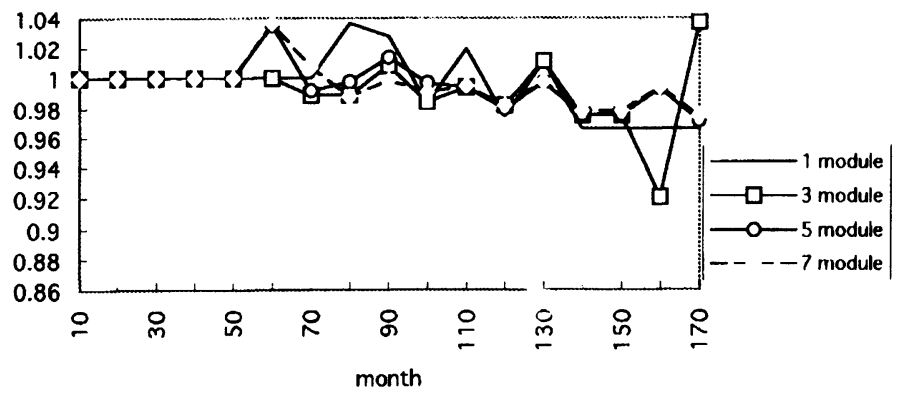

Figure 7: Evaluation of energy consumption.

In order to verify feasibility of PMPP, it is necessary to carry out many more simulations. In this simulation, number of modules and their life time are the only variables. One of the effects 
of changes of these parameters denote that with a increasing number of modules the volume of disposal decreases. Another effect is that longer average life time of product decreases the volume of disposal. Therefore, we conclude that the simulation result shown here implies its feasibility in term of module based products. Some other interesting parameters to study would be the distribution coefficients and the consumption of energy as well as the product price.

\section{THE PENDING FACTORS}

One of our future works is to include the following factors into the simulation model.

\section{Economy}

- Profit

It is important for producers to keep their profit unchanged. According to decrease in production volume, we will have to increase the profit gained from each product.

\section{- Product price}

By introducing disassembly, recycling and reuse, the production cost will increase due to more production time spent on each product. But, if the producers are regarded as fully responsible for their products and heavy taxes are introduced on disposal, the price of a traditional product will also increase.

\section{Customers}

- Habit

Today behavior of consumers is closely related to fashion and controlled by the producers. The custom of buying new products is artificially created and, therefore, can be changed. New product are mainly sold not because the old ones do not work, but simply because the new ones are looking different either in color or shape.

- Satisfaction

From the customers' point of view, there is basic desire to satisfy their needs. Since maybe $80 \%$ of the needs is artificially created, it can also be changed through consciousness and education. With a growing concern in the environmental issues it will be advantages for producers to have an "environmental stamp." But, to change our habits will take both time and a big effort.

\section{Employment}

Other points include the problem of unemployment due to the less production. But, even there will be less production new areas of work will emerge regarding disassembly, recycling and reuse. Therefore, we do not see unemployment as a pending factor.

\section{Laws and regulations}

In order to meet new demand from authorities and standardization organizations, implementation of the closed life cycle will be a indispensable. It do not mean that every factory has to deal with their own disposal, but that the producer is fully responsible for it. In order to make the recycling business profitable, some companies has to be specialized in this area. In Europe the most fast growing business is the environmental business.

\section{Implementation}

On of the big challenges in sustainable development is to educate engineers for a new way of thinking. Achieving global sustainable production and consumption require sustainable 
structural changes over a long term. There is no doubt that the related changes have to take part already in the designing process, and that may be the most pending factor for implementation.

\section{CONCLUSION}

In this paper, we have presented a life cycle simulation tool. The result, gained so far, indicates that there is a significant reduction in the volume of waste and consumption of energy and material by introducing module based products. Future works include to add environmental effects to each process in order to support the inventory analysis in the life cycle assessment. This will lead us to develop indisputable tool to support designers to plan product life cycle at the very early stage of design.

\section{REFERENCES}

Hentshel, C. (1993) The greening of products and production: a new challenge for engineering, Proceedings of International conference on advances in Production Management system.

Tomiyama, T., Sakao, T., Umeda, Y. and Baba, Y. (1996), The post mass production paradigm, knowledge intensive engineering, and soft machines, Life cycle modeling for innovative products and processes, Chapman \& Hall, London, pp. 367-379. 